\title{
Anti-malarial market and policy surveys in sub-Saharan Africa
}

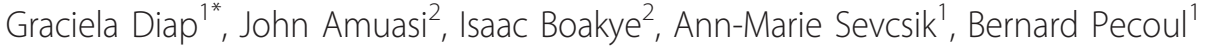 \\ From Meeting on Public and Private Antimalarial Markets and Policy Surveys \\ Geneva, Switzerland. 18 September 2009
}

\begin{abstract}
At a recent meeting (Sept 18, 2009) in which reasons for the limited access to artemisinin-based combination therapy (ACT) in sub-Saharan Africa were discussed, policy and market surveys on anti-malarial drug availability and accessibility in Burundi and Sierra Leone were presented in a highly interactive brainstorming session among key stakeholders across private, public, and not-for-profit sectors. The surveys, the conduct of which directly involved the national malaria control programme managers of the two countries, provides the groundwork for evidence-based policy implementation. The results of the surveys could be extrapolated to other countries with similar socio-demographic and malaria profiles. The meeting resulted in recommendations on key actions to be taken at the global, national, and community level for better ACT accessibility. At the global level, both public and private sectors have actions to take to strengthen policies that lead to the replacement of loose blister packs with fixed-dose ACT products, develop strategies to ban inappropriate antimalarials and regulate those bans, and facilitate technology and knowledge transfer to scale up production of fixed-dose ACT products, which should be readily available and affordable to those patients who are in the greatest need of these medicines.

At the national level, policies that regulate the anti-malarial medicines market should be enacted and enforced. The public sector, including funding donors, should participate in ensuring that the private sector is engaged in the ACT implementation process. Research similar to the surveys discussed is important for other countries to develop and evaluate the right incentives at a local level.

At the community level, community outreach and education about appropriate preventive and treatment measures must continue and be strengthened, with service delivery systems developed within both public and private sectors, among other measures, to decrease access to ineffective and inappropriate anti-malarial medicines.

What was clear during the meeting is that continuing commitment, strengthened interaction and transparency among various stakeholders, with focus on communities, national governments, and evidence-based policy and action are the only way to sustainably address the control of malaria, a disease which continues to have a significant health and socio-economic impact worldwide, particularly in sub-Saharan Africa.

Details on the methodology employed in carrying out the studies discussed at this meeting, as well as more detailed results, data analysis and discussion of the studies are soon to be published.
\end{abstract}

\footnotetext{
* Correspondence: gdiap@dndi.org

${ }^{1}$ Drugs for Neglected Diseases initiative (DNDi), Geneva, 1202, Switzerland
}

\section{Biomed Central}

(C) 2010 Diap et al; licensee BioMed Central Ltd. This is an open access article distributed under the terms of the Creative Commons Attribution License (http://creativecommons.org/licenses/by/2.0), which permits unrestricted use, distribution, and reproduction in any medium, provided the original work is properly cited. 


\section{Background}

Globally, 247 million clinical episodes of malaria are estimated to occur every year, of which $86 \%$ are in subSaharan Africa. Of more than 767,000 (5th-95th percentiles: 621,000-902,000) Africans who are estimated to have died from malaria in 2008, $88 \%$ were children under five years of age, which equals to one child dying of malaria every 45 seconds [1].

Access to artemisinin-based combination therapy (ACT) is still limited in Africa, even though it has been recommended by WHO since 2001 as the first-line treatment for uncomplicated malaria [2]. Substantial progress has been made in the past five years in the number of sub-Saharan African countries that have now adopted ACT as first-line treatment [3]. As of September 2009 [4], 81 countries have adopted ACT and 69 countries have deployed them (Figure 1).

However, access to appropriate anti-malarial drugs remains inadequate as has been shown by recent household studies in several African countries [1]. Moreover, scarce data exist on the availability (in terms of concentration and pricing) of different forms of $\mathrm{ACT}$ in many areas across sub-Saharan Africa.
To better understand where access is still limited, policy and market surveys on anti-malarial drug availability and accessibility were done in selected countries where the ACT artesunate and amodiaquine (AS+AQ) has been adopted as first-line treatment of uncomplicated Plasmodium falciparum malaria.

At the meeting organized and hosted by Drugs for Neglected Disease initiative (DNDi) in Geneva, Switzerland, on Sept 18, 2009 (see Additional file 1), surveys undertaken in Burundi from 1 to 16 March, 2009, and Sierra Leone from May 24 to June 3, 2009, were presented by the lead investigative team of Dr. John Amuasi (Research and Development Unit, the Komfo Anokye Teaching Hospital [KATH], Ghana) and Dr. Graciela Diap (DNDi, Geneva, Switzerland).

Results from these two surveys in sub-Saharan Africa served as the launching point for a highly interactive discussion among more than 30 experts from national malaria control programmes (NMCPs) in Africa, WHO, Roll Back Malaria (RBM), Health Action International (HAI), UNITAID, The Global Fund, Medicines for Malaria Venture (MMV), Malaria Consortium, sanofiaventis, Médecins-Sans-Frontières (MSF), Clinton HIV/

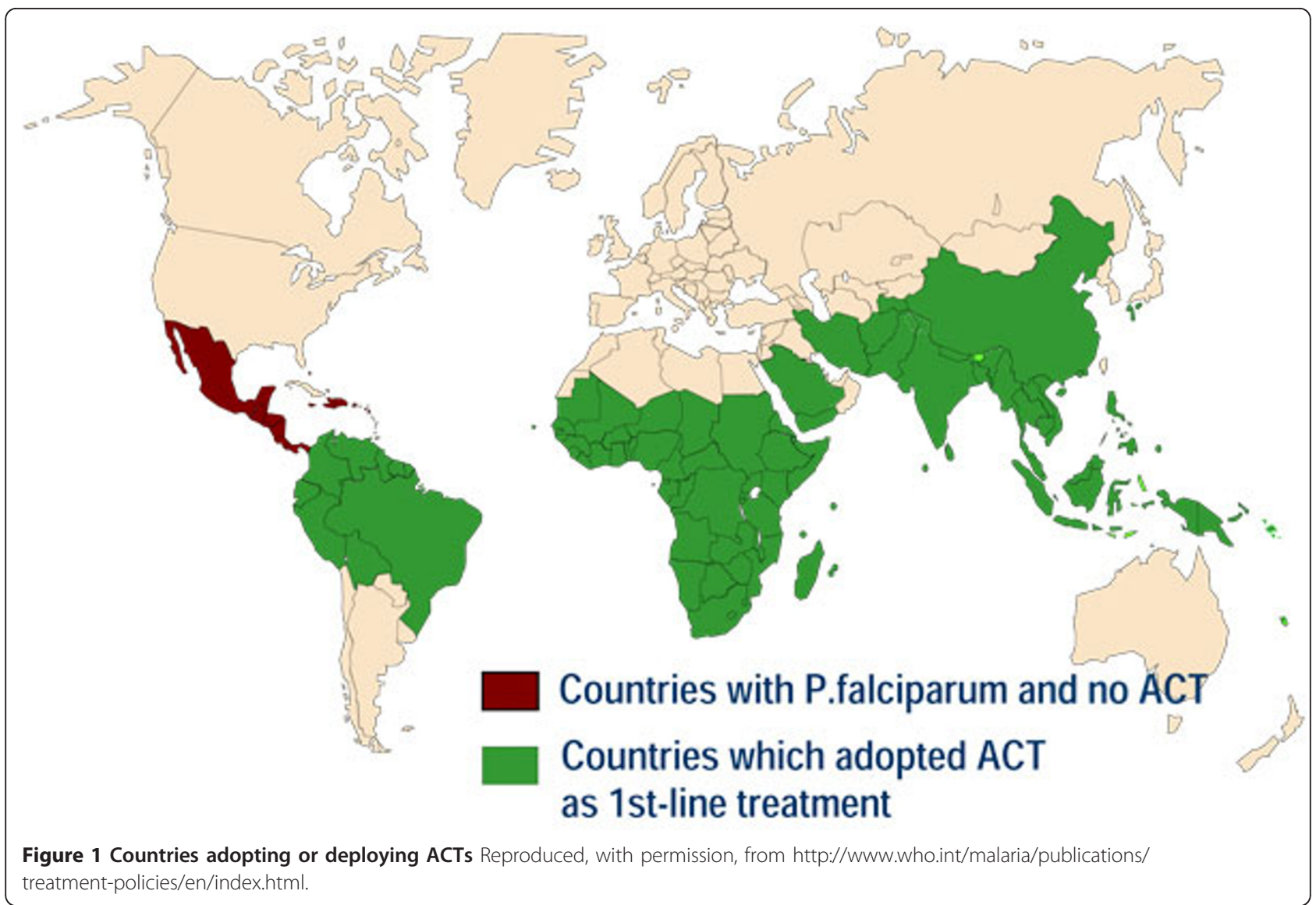


AIDS Initiative (CHAI), UNICEF, and Population Services International (PSI).

Co-chaired by Dr. Olusoji Adeyi, the AMFm Unit Director of The Global Fund to Fight AIDS, Tuberculosis and Malaria, Dr. Angus Spiers, Regional Tuberculosis and Malaria Advisor for UNICEF ESARO, Kenya, and Dr. Bernard Pecoul, the Executive Director of DNDi, the main objectives of the meeting were to:

- share results from the anti-malarial market (public and private) and policy surveys in Burundi and Sierra Leone;

- discuss how results from the Burundi and Sierra Leone surveys could be used to optimize ACT distribution at the community level, and through public and private sector channels in Africa;

- discuss key issues to improve the rational use of ACT;

- conceptualize areas of actions to facilitate deployment of ACT at the global, national, and community level.

Although there is increasing interest in eliminating malaria, there are also some countries at risk of being left behind because of political instability, lack of Global Fund eligibility, or disinterest/absence of pharmaceutical industries within the country.

From the lessons of past experiences with the antimalarial chloroquine, the therapeutic life of ACT needs to be reinforced at the community level [5]. To that end, WHO policies to implement ACT include: preservation of the useful therapeutic life of ACT, optimization of ACT effectiveness, delay or prevention of resistance, use of ACT of proven quality, and reclassification of ACT to over-the-counter status (responsibly) to ensure availability and accessibility.

Combination therapies for malaria are of public health importance in Africa. It is, therefore, necessary that
ASAQ [6,7] the fixed-dose combination of AS+AQ, at a no-profit/no-loss price launched by DND $i$ and sanofiaventis, and other combination therapies become rapidly and widely accessible to patients who need it the most in both rural and urban Africa. Currently, 25 African countries are either undergoing the registration process or have already registered ASAQ Winthrop ${ }^{\circ}$. Sanofiaventis reports that 12.6 million treatments of ASAQ Winthrop ${ }^{\circ}$ have been delivered to the public sector of 15 African countries between January and August 2009. 25-30 million treatments are forecasted to have been delivered by the end of 2009 , and $40-55$ million treatments will be delivered by the end of 2010 . Those forecasts are thus far limited to the public sector. To assure that there can be a successful implementation of ASAQ in countries at risk of being left behind, DND $i$ and $\mathrm{KATH}$, together with the respective country's NMCPs, surveyed the current malaria market situation of Burundi and Sierra Leone, where AS+AQ has been adopted as first-line treatment for uncomplicated $P$. falciparum malaria.

\section{Methods for conducting the surveys}

Adapted WHO-HAI methodologies [8] were used to analyse data in public and private sectors. Data were obtained by reviewing publications, interviewing relevant health stakeholders, and visiting 70 retail drug outlets in Burundi and 127 in Sierra Leone.

With WHO-HAI methodologies adapted for each country, based on the uniqueness of the in-country health systems, two strikingly different situations emerged (Table 1).

\section{Results of the surveys \\ Burundi}

Burundi in the east African sub-region is one of the smallest countries in Africa and has a population of approximately 8.7 million people. Malaria remains a

Table 1 Surveys in a nutshell

\begin{tabular}{|c|c|c|}
\hline & $\begin{array}{l}\text { Burundi - March } 09 \\
3 \text { survey areas }\end{array}$ & $\begin{array}{l}\text { Sierra Leone - June } 09 \\
6 \text { survey areas }\end{array}$ \\
\hline Malaria cases/year [1] & 2.3 million & 2.3 million \\
\hline Population & 8.7 million & $\sim 6.4$ million \\
\hline Geographic area & $27.830 \mathrm{~km}^{2}$ & $71.740 \mathrm{~km}^{2}$ \\
\hline Public \& private outlets assessed & 70 & 127 \\
\hline Availability of AS+AQ (as \% of all types of outlets) & $25.1 \%$ & $30.9 \%$ \\
\hline Median price of $\mathrm{AS}+\mathrm{AQ}^{*}$ & $\begin{array}{l}\text { Public: median - US\$0.16(0.00-2.42) } \\
\text { Private: median - US\$0.40 (0.17-2.82) }\end{array}$ & $\begin{array}{l}\text { Public: median - US\$1.56 (1.56-2.50) } \\
\text { Private: median - US\$1.56 (0.16-6.25) }\end{array}$ \\
\hline ACTs' dispensers' knowledge on indications for ACTs use & $\begin{array}{l}94 \% \text { of public sector correct } \\
\text { Only } 39 \% \text { of private sector correct }\end{array}$ & $\begin{array}{l}71.9 \% \text { of public sector correct } \\
\text { Only } 15.9 \% \text { of private sector correct }\end{array}$ \\
\hline ASAQ Winthrop ${ }^{\circledast}$ registered & Yes, delivered in March 2009 but not yet distributed $†$ & Process ongoing by October 2009t \\
\hline
\end{tabular}

*Presented as public/private and overall because of policy differences between countries.

†These data were obtained at the time of the meeting. 
major public health problem and is of great concern in Burundi, where an epidemic during 2000-01 has resulted in approximately 1,000 deaths every day over the course of the epidemic $[9,10]$. Access to ACT remains limited in Burundi where malaria is the leading cause of infant deaths, being $47 \%$ of all deaths [11].

Burundi currently runs a three-tier healthcare administrative system - central, intermediate, and peripheral. The central level determines the policy and strategy of interventions, as well as the administration and quality of the health system. The intermediate level recommends policy to the cabinet and coordinates the implementation of policy within regions and sectors. The peripheral level is composed of all the health centres across the country. About $33 \%$ of all health centres are privately owned, playing an important role in health-service delivery [12].

Burundi has adopted AS+AQ combination therapy as first-line therapy for the treatment of uncomplicated malaria, and quinine tablets/injections for complicated malaria as of December 2003, as its national anti-malarial treatment policy. A fixed-dose formulation of ASAQ Winthrop ${ }^{\circ}$ has already been registered in Burundi for public sector distribution, whereas for the private sector (ASAQ brand name Coarsucam ${ }^{\circ}$ ) has not yet been authorized for sale (Table 2). The NMCP and the Ministry of Health aim to have the same price for ACT in both private and public sectors. The first orders of ASAQ Winthrop were placed for 1.7 million treatments, costing up to US $\$ 1$ million. In addition, the Burundi Government continues to accept donations of non-fixed-dose, non-prequalified AS+AQ. In the difficult-to-regulate private sector, an unauthorized system runs in parallel to the formal structure of the drug distribution system in Burundi and includes an irrational prescription of essential medicines.

In the public sector, the Government subsidizes each treatment course of AS+AQ so that it costs $200 \mathrm{FBU}$
(US\$0.16) to the patient. In addition, treatment is offered free for children younger than five years of age. At the time of the survey, there was no existing policy on free treatment for children older than five years of age. This was also the finding for pregnant women, for whom quinine is the first-line treatment. However, according to the NMCP, this policy has since changed and pregnant women are now also eligible for the free anti-malarial service.

Currently, The Global Fund and UNICEF procure ACTs and rapid diagnostic tests for the NMCP. The central medical store of the Ministry of Health stocks quinine, which is self-procured. Anti-malarial drugs for children under five years of age come mainly from The Global Fund. It is planned that the proposed repackage of ASAQ Winthrop for provision at the same price to the private market will be supported by $10 \%$ of The Global Fund budget.

In Burundi, $\mathrm{AS}+\mathrm{AQ}$ represented a quarter of the antimalarials surveyed (Table 2). Quinine tablets are the most common anti-malarial drugs, and are equally present across both public and private sectors. Quinine injections also represented a quarter of the anti-malarials surveyed. AS+AQ was more likely to be found in the public $(34.8 \%)$ than in the private sector $(13.5 \%)$ $(\mathrm{p}<0.001)$. Halofantrine, which is not part of the national policy, was much more present in the private than in the public sector (Table 2). This observation is alarming because of potential adverse cardiac effects of halofantrine [13]. Its availability also leads to concerns about the potential cross-resistance with lumefantrine (LUM) and mefloquine (MQ) [14,15], which could also have a devastating effect on the future deployment of artemether $(\mathrm{AR})+\mathrm{LUM}$ and $\mathrm{AS}+\mathrm{MQ}$.

The median price of the recommended AS+AQ firstline treatment was similar in the governmental and charity sectors (US\$0.16), and 2.5-fold higher in the private sector (Table 3 ). The median price of quinine

Table 2 Availability of anti-malarial drugs in Burundi (70 outlets), by public and private sector

\begin{tabular}{|c|c|c|c|}
\hline & $\begin{array}{l}\text { Number of anti-malarial drugs in } \\
\text { outlets surveyed }(n=243)\end{array}$ & $\begin{array}{l}\text { Number of anti-malarial drugs in the } \\
\text { public sector }(n=132)\end{array}$ & $\begin{array}{l}\text { Number of anti-malarial drugs in the } \\
\text { private sector }(n=111)\end{array}$ \\
\hline Amodiaquine (AQ) & $1(0.4 \%)$ & 0 & $1(0.9 \%)$ \\
\hline $\begin{array}{l}\text { Artemether+lumefantrine } \\
\text { (AR+LUM) }\end{array}$ & $3(1.2 \%)$ & 0 & $3(2.7 \%)$ \\
\hline $\begin{array}{l}\text { Artesunate+amodiaquine } \\
(\mathrm{AS}+\mathrm{AQ})\end{array}$ & $61(25.1 \%)$ & $46(34.8 \%)$ & 15 (13.5\%) \\
\hline $\begin{array}{l}\text { Dihydroartemisinin }+ \\
\text { piperaquine }(\mathrm{DHA}+\mathrm{PQ})\end{array}$ & $1(0.4 \%)$ & 0 & $1(0.9 \%)$ \\
\hline Dihydroartemisinin (DHA) & $4(1.6 \%)$ & 0 & $4(3.6 \%)$ \\
\hline Halofantrine & $16(6.6 \%)$ & $2(1.5 \%)$ & $14(12.6 \%)$ \\
\hline Quinine injection & $54(22.2 \%)$ & $29(22.0 \%)$ & $25(22.5 \%)$ \\
\hline Quinine tablets & $103(42.4 \%)$ & $55(41.7 \%)$ & 48 (43.2\%) \\
\hline
\end{tabular}

Data are $\mathrm{n}(\%)$. 
Table 3 Pricing of anti-malarial drugs in Burundi, by sector

\begin{tabular}{lll}
\hline Survey area & $\begin{array}{l}\text { Number of } \\
\text { outlets }\end{array}$ & $\begin{array}{l}\text { Median price, US\$ } \\
\text { (range) }\end{array}$ \\
\hline $\begin{array}{l}\text { Government/Public } \\
\text { Sector }\end{array}$ & & \\
$\quad$ AS+AQ & 31 & $0.16(0.00-0.16)$ \\
$\quad$ Halofantrine & 2 & $8.90(8.35-9.44)$ \\
$\quad$ Quinine injection & 20 & $0.24(0.00-0.48)$ \\
Charity & & \\
AS+AQ & 15 & $0.16(0.08-2.42)$ \\
Quinine injection & 9 & $0.32(0.16-0.81)$ \\
Quinine tablets & 1 & $1.66(0.51-2.58)$ \\
Private & & $0.32(0.32-0.32)$ \\
AQ & 1 & $0.60(0.40-0.81)$ \\
AM+LUM & 2 & $0.40(0.17-2.82)$ \\
AS+AQ & 7 & $2.82(2.82-2.82)$ \\
DHA+PQ & 1 & $4.84(4.84-4.84)$ \\
Dihydroartemisinin & 1 & $4.03(4.03-4.84)$ \\
Dihydroartemisinin* & 3 & $9.68(8.47-9.68)$ \\
Halofantrine & 3 & $9.68(7.66-11.29)$ \\
Halofantrine* & 11 & $0.40(0.24-1.61)$ \\
Quinine injection & 17 & $1.61(0.32-3.39)$ \\
Quinine tablets & 29 &
\end{tabular}

For tablets the price is for a course; for injections is for a single injection. The price per course is neither for adults nor for adolescents or children. Often when an adult treatment is not available; multiple adolescent or child doses are given to supplement and vice-versa.

*These were found in stand-alone pharmacies that were not attached to, or part of, any health facility.

tablets and injections was also higher in the private sector compared with that in public and charitable sectors. Surprisingly, quinine is being used as first-line treatment for uncomplicated malaria in both public and private sectors, despite the fact that it is more expensive than subsidized ACT. The reason for this could be that quinine has been available for much longer and people are more familiar with this drug than with ACT, or that there could be a higher profit margin for quinine than for ACT for the distributors.

Across all three surveyed regions (Bujumbura, Bururi and Kayanza) and sectors in Burundi, more than $50 \%$ of retailers were familiar with $\mathrm{ACT}$, with the highest knowledge in the charitable sector $(90 \%)$ and the lowest in the private sector (55\%). Knowledge of WHO malaria treatment and national guidelines was especially low in the private sector and among consumers.

The following is a summary record of the questionand-answer session that took place during the Burundi survey presentation:

- What was the pricing of artesunate (AS) monotherapy, and how large was its market share?
Response: Average price was US\$0.32, and it represented $1.6 \%$ of anti-malarials found within the survey. This price corresponds to a complete treatment and is found only in the private sector.

- Is there a lot of variation in the pricing of ACTs in the charitable sector?

Response: Although this was not expected because the charitable sector should have the same free/subsidized policy as the public sector, prices varied widely.

- Were anti-malarials really distributed for free for children under five years of age and pregnant women, and subsidized for the rest of the population in the public sector?

Response: Yes.

- Do the vendors in the private sector influence or bias the purchaser's decision?

Response: Yes, but there are many confounding factors which may influence the purchaser's posture and the vendor's influence, making this highly subjective.

- The public sector dispensor's knowledge of ACT was impressive compared with that of the private sector. Was this influenced by ASAQ training?

Response: Since 2003, public training has been available for ACT implementation, but much less in the private sector.

- Based on WHO-HAI methodology, the minimum number of outlets is generally 120 to be surveyed, why were only 70 outlets in Burundi?

Response: The number of outlets surveyed depended on the density of the population and the size of the country, and this was representative in the three areas surveyed.

- What is the reward of the private pharmacists when they distribute quinine rather than $\mathrm{AS}+\mathrm{AQ}$ ?

Response: ACTs were not widely available in the private sector; if ACT were available; they were mostly being smuggled into the country or leaked from the public sector.

- Was it possible to differentiate retailers from dispensers? 
Response: Not in these surveys - varying definitions can make it difficult.

- Were products other than anti-malarials compared on the market?

Response: No comparator drugs were used in the surveys.

- Why was there a general preference for quinine?

Response: Quinine has been widely available for a long time. Chloroquine was banned six years ago and was not found on the market, which was reassuring.

\section{Sierra Leone}

Located on the west coast of Africa, Sierra Leone is a small country where three-fourths of the population of about 6.4 million people live below the poverty line of US $\$ 1$ per day, and where infant and maternal mortality are among the highest in Africa. Access to ACTs is limited in Sierra Leone, where malaria is one of the leading causes of morbidity and mortality.

In Sierra Leone, $77 \%$ of people can access primary health services [16]. A visit to the formal health sector can cost three times the average daily wage. Trained health workers are lacking at all community levels, especially in rural areas. The healthcare system is poorly used, with out-of-pocket expenses remaining one of the highest in Africa (70\%). The final drug cost to the patient is $180 \%$ of the landed cost if it originated from the central medical stores. There is a need to simplify the flow of distribution of drugs to reduce the costs to the patient.

$\mathrm{AS}+\mathrm{AQ}$ was adopted as first-line treatment for uncomplicated malaria in 2004, after which a $25 \%$ drop in malaria infection was observed over an ensuing fiveyear period [17]. Anti-malarial drugs are available at all healthcare facilities through the national Essential Drugs programme, charitable and private sectors, and are provided free of charge in all public facilities by governmental and the charitable sectors.

Currently, the NMCP is supported with US $\$ 10$ million from The Global Fund from June 2008 to May 2010 , which represents $30.7 \%$ of its entire two-year budget. To ensure correct distribution of the drugs, the Home-Based Management of Malaria Initiative was launched in 2007. Besides The Global Fund, UNICEF runs a separate ACT procurement system, which is mainly funded by the Japanese and German Governments. To fill the remaining gaps, the Government of Sierra Leone (from internally generated funds) also procures anti-malarials, mainly quinine, through central malaria stores.
In April 2009, following poor drug forecasting, difficulties in the distribution system and poor coordination among key players, about 900,000 doses of AS+AQ were destroyed, but shortages still existed at the market level, indicating the need to streamline the procurement system and coordinate these efforts. Further investigation is needed to determine the cause behind the system's failure at that time.

Of the 340 anti-malarials in the 127 outlets, only $30.9 \%$ were policy-recommended $\mathrm{AS}+\mathrm{AQ}, 20 \%$ quinine, and $20 \%$ sulphadoxine-pyrimethamine (SP). Surprisingly, chloroquine formed $12.7 \%$ of the market.

Only 19 out of the 127 surveyed outlets (15.0\%) carried all three policy-recommended anti-malarials, with the public sector performing best $(57.9 \%$ carried all three policy-recommended anti-malarials). About $86.7 \%$ of the private outlets carried no policy-recommended anti-malarials. AS+AQ was a third of the anti-malarials in the surveyed outlets, and was the most common on the market in all sectors, followed by SP (Table 4). Chloroquine, quinine, and other monotherapies including AS were still widely used as first-line treatment. The distribution of drugs was mainly a push rather than a pull system, and there was a weak control on their importation.

About $50.8 \%$ of anti-malarial drugs were dispensed over the counter. Chloroquine was mainly found over the counter $(87.7 \%)$ rather than prescription only, whereas AS+AQ was accessible more often through prescription only $(67.2 \%)$.

$\mathrm{AS}+\mathrm{AQ}$ had the highest median price of all antimalarials in the surveyed outlets (Table 5) and the lowest in the charitable sector. Although it was supposed to be free within the public sector, the median price was US\$1.56 (of the three outlets in which it was found). Quinine injection prices were the same in the public and charitable sectors and comparably higher in the private sector, whereas quinine tablets were cheapest in the public sector and increasingly more expensive in the charitable and private sectors.

Across all six surveyed regions (Bo, Kalihun, Kenema, Koinadugu, Port Loko and Western urban area) and sectors high knowledge and familiarity with ACT (>92\%) were found in the governmental and charitable sector compared with that in the private sector (73\%). In terms of WHO treatment recommendations and national anti-malarial policy, the private sector had the least knowledge (25-32\% vs $54-61 \%$ for the charitable sector and $87-89 \%$ for the public sector).

The following is a summary record of the questionand-answer session that took place during the Sierra Leone survey presentation: 
Table 4 Availability of anti-malarial drugs in Sierra Leone (127 outlets surveyed), by public, charitable and private sectors

\begin{tabular}{lllll}
\hline & $\begin{array}{l}\text { Number of anti-malarials in } \\
\text { outlets surveyed }(\mathrm{n}=340)\end{array}$ & $\begin{array}{l}\text { Number of anti-malarials in } \\
\text { government/public sector }(\mathrm{n}=141)\end{array}$ & $\begin{array}{l}\text { Number of anti-malarials } \\
\text { in mission/NGO }(\mathrm{n}=67)\end{array}$ & $\begin{array}{l}\text { Number of anti-malarials in } \\
\text { the private sector(n=132) }\end{array}$ \\
\hline AM+LUM & $3(0.9 \%)$ & 0 & $1(1.5 \%)$ & $2(1.5 \%)$ \\
AQ & $8(2.4 \%)$ & $1(0.7 \%)$ & $1(1.5 \%)$ & $6(4.5 \%)$ \\
AR & $13(3.8 \%)$ & $3(2.1 \%)$ & $4(6.0 \%)$ & $6(4.5 \%)$ \\
AS & $15(4.4 \%)$ & $2(1.4 \%)$ & $3(4.5 \%)$ & $10(7.6 \%)$ \\
AS+AQ & $100(29.4 \%)$ & $55(39.0 \%)$ & $20(29.9 \%)$ & $25(18.9 \%)$ \\
AS+MQ & $1(0.3 \%)$ & 0 & 0 & $1(0.8 \%)$ \\
AS+SP & $6(1.8 \%)$ & 0 & $1(1.5 \%)$ & $5(3.8 \%)$ \\
Chloroquine & $35(10.3 \%)$ & 0 & $4(6.0 \%)$ & $31(23.5 \%)$ \\
Halofantrine & $3(0.9 \%)$ & 0 & 0 & $3(2.3 \%)$ \\
MQ & $3(0.9 \%)$ & 0 & $1(1.5 \%)$ & $2(1.5 \%)$ \\
Proguanil & $1(0.3 \%)$ & 0 & 0 & $1(0.8 \%)$ \\
Pyrimethamine & $1(0.3 \%)$ & 0 & 0 & $1(0.8 \%)$ \\
Quinine & $67(19.7 \%)$ & $36(25.5 \%)$ & $16(23.9 \%)$ & $15(11.4 \%)$ \\
SP & $84(24.7 \%)$ & $44(31.2 \%)$ & $16(23.9 \%)$ & $24(18.2 \%)$ \\
\hline Data & & 0 & &
\end{tabular}

Data are $\mathrm{n}(\%)$.

Table 5 Pricing of anti-malarial drugs in Sierra Leone, by sector

\begin{tabular}{lll}
\hline Survey area & $\begin{array}{l}\text { Number of } \\
\text { outlets }\end{array}$ & $\begin{array}{l}\text { Median price, US\$ } \\
\text { (range) }\end{array}$ \\
\hline $\begin{array}{l}\text { Government/Public } \\
\text { Sector }\end{array}$ & & \\
$\quad$ AS+AQ & 3 & $1.56(1.56-2.50)$ \\
$\quad$ Quinine injection & 8 & $0.31(0.16-0.94)$ \\
$\quad$ Quinine tablets & 8 & $0.55(0.31-0.94)$ \\
$\quad$ SP & 4 & $0.31(0.28-0.31)$ \\
Charity & & \\
AS+AQ & 7 & $0.62(0.31-5.31)$ \\
$\quad$ Quinine injection & 8 & $0.31(0.09-0.47)$ \\
$\quad$ Quinine tablets & 9 & $0.62(0.31-1.25)$ \\
SP & 8 & $0.31(0.16-0.47)$ \\
Chloroquine tablets & 1 & $0.16(0.16-0.16)$ \\
Private & & $1.56(0.16-6.25)$ \\
AS+AQ & 28 & $0.47(0.16-0.62)$ \\
Quinine injection & 8 & $0.95(0.63-1.88)$ \\
Quinine tablets & 8 & $0.47(0.31-0.94)$ \\
SP & 29 & $0.16(0.09-1.25)$ \\
Chloroquine tablets & 24 &
\end{tabular}

For tablets the price is for a course; for injections is for a single injection. The price per course is neither for adults nor for adolescents or children. Often when an adult treatment is not available; multiple adolescent or child doses are given to supplement and vice-versa.

- What was the price difference between the drug store and the patent shops (defined by the Sierra Leone Ministry of Health more like a licensed chemical seller outlet)

Response: The most expensive average price for $\mathrm{AS}+\mathrm{AQ}$ in the pharmacies was US\$2.93, in the drug stores US\$1.88, and in patent shops US\$0.35.
- In the methodology, what is proportion of the different sectors (private, public, charitable) represented in the market share?

Response: In Sierra Leone, one needs to consider the informal sector, particularly the Chinese peddlers selling anti-malarials. In a government hospital, Chinese-made quinine injections that did not have a manufacturer name. Samples were bought. There are chloroquine tablets, combination of chloroquine and paracetamol, chloroquine injections and syrup freely available in both private outlets (pharmacies and drug shops) and mission/ NGO hospitals. Drug peddlers move from village to village selling drugs; particularly the Chinese. In districts where the system is strong (such as in Bo), they have been driven out. However, in most places they are fully operational and selling anti-malarials at will.

- How can donations be managed to reflect policy? And how can policy be made to reflect donations?

Response: Many anti-malarials are coming from donations and should be viewed with caution. Donations are being received, but decisions made by high-level decision makers may take issues other than policy into consideration.

- In Sierra Leone, was AS+AQ available in loose dose or blister packs?

Response: Only blister packs were available for AS+AQ. No loose doses were available. 


\section{Discussion}

The use of ACT should be considered as part of a bigger picture of malaria case management. The current malaria treatment guidelines formulated by the WHO [18] recommend parasite-based diagnosis for older children and adults in all malarial settings and clinical diagnosis for children under five years of age in areas of high transmission. Artemisinin-based combinations are recommended for treatment of uncomplicated $P$. falciparum malaria in all age groups, except during the first trimester of pregnancy [19].

Five formats of ACT are presently recommended: artemether and lumefantrine, artesunate and amodiaquine, artesunate and mefloquine, artesunate and sulfadoxinepyrimethamine, and dihydroartemisinin and piperaquine (DHA-PQ). DHA-PQ, which has been added in 2009, is not expected to make up a large part of the market because of approval hurdles. The clinical profile of malaria in an area determines the kind of health care services needed. If the disease occurs mainly in children, the system will focus on paediatric services. If the disease is acute, rapidly progressing and fatal, the health care services must be provided both at the level of the community for early treatment and of tertiary institutions for care for severe disease. In order to optimize the benefit of artemisinin-based combination, treatments must be available as widely as possible. Therefore, home management of malaria should be implemented in areas where there is poor access to health facilities, as the formal public health delivery system will not reach many people who need treatment. Distribution and use of ACT depends on several factors including regulatory status, ease of implementation, safety and other factors. WHO provides recommendations and guidelines for countries to reinforce implementation of ACT.

\section{Proposed interventions}

At the community level, trained community health workers could deliver pre-packaged anti-malarial drugs to children younger than five years of age. Specifically, community health workers can be trained to recognise symptoms of severity, and referred if needed, and be trained to use rapid diagnostic tests to diagnose malaria and deliver pre-packaged drugs to children. This system has been successfully carried out in past studies in the Zambia, Uganda, Cambodia, Mali, Chad, Sierra Leone, south Sudan and Ethiopia [20-24]. Malaria care should also be combined with management of other common childhood illnesses (ie, pneumonia and diarrhoea). Further evaluation of these interventions is needed.

Besides accessibility to services, accessibility to effective treatment is needed and requires effective integration into the health system. Accessibility to effective treatment may require provision of incentives to reduce attrition and improve performance with sustained community financing of central medicine distributors. Home management for malaria may offer an alternative malaria case management policy but will not be sustainable without a functioning health system.

There is a need to harmonize the work of all frontline workers, including community health workers, central medicine distributors and home management for malaria who come from different backgrounds, as well as traditional healers, to reduce non-adherence to national policies and improve performance. By motivating and mobilizing these front-line workers, ACT implementation can be scaled up. However, an assessment of what type of effective system is needed for support is required. In addition, there are almost no examples of adequate community financing for central medicine distributors; therefore, there is a need for consistent community and policy support to ensure the availability of drugs to ensure the effective function of central medicine distributors.

\section{Key issues}

The Burundi and Sierra Leone surveys highlight a lack of, or weak enforcement of, regulation of importation of anti-malarial drugs. In addition, involvement of the private sector is missing in training, planning of delivery, and poor quality of services that include: no diagnostics, lack of knowledge of correct treatment regimes per national and WHO policy, unnecessary treatment sales, and high costs to the patient.

For widespread ACT implementation, the private sector needs to be acknowledged and engaged with implementation plans. By doing so, it will facilitate stopping sales of non-recommended anti-malarials that include monotherapies and fake drugs. A system should be put in place and enforced so that those who sell unauthorized anti-malarials are legally prosecuted. To provide effective treatment, compulsory training programmes could be launched for the private sector to improve proper diagnosis, treatment and referral in severe cases. Other options may include incentivizing or subsidizing the costs of drugs sold in the private sector, making them cheaper for the consumer. As a first step, it may also be relevant to understand why consumers prefer to go to the private sector to purchase their drugs rather than to public sector facilities. In addition, consumers need to be educated because the responsibility of correct treatment does not lie only with the distributors but also with the consumer themselves, which will demand high quality and correct treatments.

As a pilot study, Uganda's Ministry of Health, in collaboration with MMV, is evaluating the effects of ACT 
uptake by offering subsidized ACT to the private sector [25]. Data were obtained from interviews, retail audit, health facility audit, as well as household surveys. Interim results show that subsidized $\mathrm{ACT}$ erode the chloroquine market share for anti-malarial drugs for children younger than five years of age, and subsidized anti-malarial drugs now account for half of all antimalarials purchased for people over five years of age.

Similar research is needed in other countries to evaluate different incentives to increase ACT uptake. To optimize data collection and usefulness, methodologies should be flexible yet robust to best meet the research need and policy demands across different countries.

\section{Outcomes}

These surveys were carried out in two countries where the communities were in hard-to-reach areas, which mean these populations are often neglected because difficult to access. The studies directly involved the NMCP project managers in the country: the value of the obtained data and the key participation on NMCPs could facilitate policy change and greater action for widespread ACT implementation. The surveys provides the groundwork for evidence-based policy implementation, which could be translated to other countries with similar socio-demographic and malaria profiles.

Limitations of the studies include the subjectivity of some of the questions used as well as selection bias of the outlets given the short duration of the study period (two weeks), with less than one hour spent at each of the outlets surveyed. In addition, no drug was used for comparison with the anti-malarials evaluated; therefore, it is unclear whether the pricing, availability and affordability of anti-malarials reflect the general situation of all drugs distributed in the outlet or is specific for antimalarials. Lack of product quality assessment is an additional limitation of the study.

\section{Recommendations}

During the meeting, information sharing with various key members provided great value for the participants and for those conducting the research. Based on discussions related to the outcomes from the Burundi and Sierra Leone surveys, the meeting made the following recommendations and proposed areas of actions at the global, national, and community level for improved ACT implementation.

\section{Global actions}

- Technology transfer to local manufacturers in subSaharan Africa

- Development of a funding strategy to give preference to fixed-dose combination ACT with a defined time period to phase out non-fixed-dose combination ACT

- Development of a strategy to regulate banned arteminin-based combinations from entering into the market

- Inclusion of education and training for all ACT supply lines, emphasizing the private sector

- Formalization of all sectors (public, private, charitable, and informal) to reach widespread dissemination of ACT

- Possibility of a worldwide ban on the manufacture, importation and sale of AS monotherapies

- Write to WHO Committee on Essential Medicine List Selection to recommend issuing guidelines for fixed-dose combination to remove the inclusion of blister packages. If removed from the Essential Medicine List, the blister packages cannot be pre-qualified and, therefore, will not be purchasable by governments benefiting from the Global Fund provisions.

\section{National actions}

- National policy should regulate the ACT market

- Private sector should be engaged in the ACT implementation process: both donors and public sector must engage

- Possible incentives for private sector providers to establish facilities in remote areas where ACT is difficult to access

- Establishment of ACT donation guidelines to reflect national anti-malarial policy for donation programmes in the spirit of the WHO Guidelines for Drug Donations

- Possible removal of tariffs before the taxes for imported ACT

- Research similar to this is needed in other countries to evaluate different incentives to increase ACT uptake

\section{Community actions}

- Education of the community about preventive and treatment measures-bed nets and ACT

- Development of a service delivery system for diagnosis, treatment, and follow-up within both public and private sectors

- Creation of a network for diagnosis and treatment

- Possible incentives for ACT distributors (i.e. community health workers) if ACT is to be disseminated for free

- Transparency on how ACT is paid for in terms of drug and service delivery 
- Development of a common framework to harmonize the public, private and charitable sectors in ACT implementation

- To decrease of access to "bad" drugs, availability and affordability of effective treatment need to be increased

- To ensure quality of treatment and management, compliance measures should be improved

- Evaluation of an integrated approach for ACT implementation that could include the role of the community health worker with minimal training as they have been effective in managing other diseases, such as anti-retroviral treatment of HIV patients

- Further evaluation of these interventions are needed

- Harmonization of the work of all frontline workers

- Similar research is needed in other countries to evaluate different incentives to increase ACT uptake

Additional file 1: Title: Meeting On Public and Private Markets and Policy Surveys Description: Document containing meeting details and list of meeting participants

\section{List of abbreviations used}

ACTs: artemisinin-based combination therapies; AQ: amodiaquine; AR: artemether; AS: artesunate; CHAl: Clinton HIV/AIDS Initiative; DHA: dihydroartemisinin; DNDi: Drugs for Neglected Disease initiative; HAl: Health Action International; KATH: Komfo Anokye Teaching Hospital; LUM: lumefantrine; MMV: Medicines for Malaria Venture; MQ: mefloquine; MSF: Médecins Sans Frontières; NGO: non-governmental organization; NMCP national malaria control programme; PQ: piperaquine; PSI: Population Services International; RBM: Roll Back Malaria; SP: sulfadoxine-pyrimethamine.

\section{Acknowledgements}

We thank the Burundian health sector (Dr. Jeanne Karenzo and Lievin Nsabiyumva, Mr. Hypax Mbanye, Mr. Adelin Uwitonze, Dr. Ignace Bimenyimana, Dr. Baza Dismas), the Sierra Leonean health sector (Dr. Amara Jambai, Dr. Samuel Baker, Dr. Magnus Gborie, Dr. Edward B. Magbity, Mr. Harold Thomas, Mrs. Wani Kumba Lahai and the MSF office in Free Town), the Komfo Anokye Teaching Hospital (Dr. Anthony Nsiah-Asare, Dr. Patrick Karikari, Dr. Samuel Blay Nguah, Mr. Alexander Deley, Mr. Bernard Arhin) and Drugs for Neglected Diseases initiative (Dr. Jean-René Kiechel, Dr. Florence Camus Bablon and Ms. Violaine Dallenbach).

We also acknowledge meeting participants and presenters, and Ms. Karly Louie and Dr. Federica Giovannini for their editorial support.

This article has been published as part of Malaria Journal Volume 9 Supplement 1, 2010: Meeting on Public and Private Antimalarial Markets and Policy Surveys. The full contents of the supplement are available online at http://www.malariajournal.com/supplements/9/S1/S1.

\section{Author details}

'Drugs for Neglected Diseases initiative (DNDi), Geneva, 1202, Switzerland. ${ }^{2}$ Komfo Anokye Teaching Hospital (KATH), Kumasi, P.O. BOX KS 1934, Ghana.

\section{Authors' contributions}

GD and JA conceived the study, and participated in its design and coordination and helped to draft the manuscript. IB participated in the design of the study and helped perform the statistical analysis. A-MS participated in the design and coordination of the meeting and helped to draft the manuscript. BP has made intellectual contributions to the study conception and analysis of results, and has been involved in critically revising the reports before presenting the data in September.

\section{Competing interests}

The authors declare that they have no competing interests.

Published: 23 April 2010

\section{References}

1. World Health Organization (WHO): World Malaria Report. 2009 [http:// whqlibdoc.who.int/publications/2009/9789241563901_eng.pdf].

2. Antimalarial Drug Combination Therapy - Report of a WHO Technical Consultation. 2001 [http://www.who.int/malaria/publications/atoz/ who_cds_rbm_2001_35/en/index.html].

3. World Health Organization (WHO): World Malaria Report. 2009 [http:// www.who.int/malaria/world_malaria_report_2009/en/index.html].

4. World Health Organization (WHO). [http://www.who.int/malaria/ publications/treatment-policies/en/index.html].

5. Whitty CJ, Chandler C, Ansah E, Leslie T, Staedke SG: Deployment of ACT antimalarials for treatment of malaria: challenges and opportunities. Malar J 2008, 7(Suppl 1):S7.

6. Pécoul B, Sevcsik A, Amuasi J, Diap G, Kiechel JR: The story of ASAQ: the first antimalarial product development partnership success. Health Partnerships Rev 2008, 77.

7. [http://www.actwithasaq.org].

8. World Health Organization (WHO). [http://www.who.int/medicines/areas/ access/medicines_prices08/en/index.html].

9. Gerstl S, Cohuet S, Edoh K, Brasher C, Lesage A, Guthmann JP, Checchi F: Community coverage of an antimalarial combination of AS and amodiaquine in Makamba Province, Burundi, nine months after its introduction. Malar J 2007, 6:94.

10. Guthmann JP, Bonnet M, Ahoua L, Dantoine F, Balkan S, van Herp M, Tamrat A, Legros D, Brown V, Checchi F: Death rates from malaria epidemics, Burundi and Ethiopia. Emerg Infect Dis 2007, 13:140-143.

11. République de Burundi Ministère de la Sante Publique: Plan National De Développement Sanitaire 2006-2010. 2006.

12. Ministère de la Sante Publique: La prise en charge du paludisme au Burundi: module de formation à l' intention des prestataires des soins. Bujumbura, Burundi. 2003.

13. Bouchaud O, Imbert P, Touze JE, Dodoo AN, Danis M, Legros F: Fatal cardiotoxicity related to halofantrine: a review based on a worldwide safety data base. Malar J 2009, 8:289.

14. Basco LK, Tahar R, Ringwald P: Molecular basis of in vivo resistance to sulfadoxine-pyrimethamine in African adult patients infected with Plasmodium falciparum malaria parasites. Antimicrob Agents Chemother 1998, 42:1811-1814.

15. Pradines B, Hovette P, Fusai T, Atanda HL, Baret E, Cheval P, Mosnier J, Callec A, Cren J., Amalvict R, Gardair JP, Rogier C: Prevalence of in vitro resistance to eleven standard or new antimalarial drugs among Plasmodium falciparum isolates from Pointe-Noire, Republic of the Congo. J Clin Microbiol 2006, 44:2404-2408.

16. Sierra Leone Government: National Health Sector Strategic Plan, 2010-15. Ministry of Health and Sanitation 2009.

17. National Malaria Control Programme. Sierra Leone Government: Malaria Baseline Survey. Ministry of Health and Sanitation 2005.

18. World Health Organisation (WHO): Malaria case management: operations manual. 2009 [http://www.who.int/malaria/publications/atoz/ 9789241598088/en/index.html].

19. World Health Organisation (WHO). [http://www.who.int/malaria/ publications/atoz/malaria_case_management_operations manual.pdf].

20. Chanda P, Hamainza B, Mulenga S, Chalwe V, Msiska C, Chizema-Kawesha E: Early results of integrated malaria control and implications for the management of fever in under-five children at a peripheral health facility: a case study of Chongwe rural health centre in Zambia. Malar $J$ 2009, 8:49.

21. Barnes Kl, Chanda P, Ab Barnabas G: Impact of the large-scale deployment of artemether/lumefantrine on the malaria disease burden in Africa: case studies of South Africa, Zambia and Ethiopia. Malar J 2009, 8(Suppl 1):S8.

22. Zurovac D, Tibenderana JK, Nankabirwa J, Ssekitooleko J, Njogu JN, Rwakimari JB, Meek S, Talisuna A, Snow RW: Malaria case-management 
under artemether-lumefantrine treatment policy in Uganda. Malar J 2008, 7:181.

23. Yeung S, Van Damme W, Socheat D, White NJ, Mills A: Cost of increasing access to artemisinin combination therapy: the Cambodian experience. Malar J 2008, 7:84

24. Hopkins H, Talisuna A, Whitty CJ, Staedke SG: Impact of home-based management of malaria on health outcomes in Africa: a systematic review of the evidence. Malar J 2007, 6:134.

25. Medicines for Malaria Venture (MMV): Unforgettable launch of MMV-MOH Uganda Pilot. [http://www.mmv.org/article.php3?id_article=527].

doi:10.1186/1475-2875-9-S1-S1

Cite this article as: Diap et al:: Anti-malarial market and policy surveys in sub-Saharan Africa. Malaria Journal 2010 9(Suppl 1):S1.

Submit your next manuscript to BioMed Central and take full advantage of:

- Convenient online submission

- Thorough peer review

- No space constraints or color figure charges

- Immediate publication on acceptance

- Inclusion in PubMed, CAS, Scopus and Google Scholar

- Research which is freely available for redistribution

Submit your manuscript at www.biomedcentral.com/submit 